Wilhelm Giese: Sierra y Campiña de Cádiz. Una contribución histórica y etnolingüistica a la investigación de Andalucia, Introducción y traducción de Manuel Rivas Zancarrón, Servicio de Publicaciones de la Universidad de Cádiz, 1996, ISBN 84-7786-379-2.

\section{SIN NOTICIAS DE GIESE}

\section{Clristoph Ehlers n los años veinte y Universidad de Sevilla treinta se publican} trabajos importantes sobre aspectos lingüisticos, etnológicos y folklóricos de Andalucia y la provincia de Cádiz. Entre ellos se encuentra el prolifico estudio del romanista Wilhelm Giese (Alsacia 1895-Hamburgo 1992), Nordost-Cádiz. Ein kulitunwissenschaftlicher Beitrag zur Erforschung Andalusiens (1937) que ha sido comentado y traducido con buen criterio por M. Rivas Zancarrón, profesor de lingüistica de la Universidad de Cádiz.

En palabras del propio autor alemán, su trabajo "venia a suplir la falta de una presentación científica de la cultura popular andaluza", laguna que contrastaba ya por entonces llamativamente con el hecho de que "Andalucia es el paisaje español que, con mucho, más atrae al viajero. El número de descripciones turisticas y obras generales que se ocupan de aspectos generales de los grandes centros urbanos andaluces es, dicho sea con justicia, considerable" (Giese 1996:33). Asi que Giese expone con minuciosidad, no exento de la sequedad y las repeticiones caracteristicas en este tipo de textos, pero tambièn a veces con amenidad e incluso humor, un inmenso acopio de datos referentes a distintos aspectos de la cultura popular andaluza de la época, que se reparte en diez capitulos: paisaje y población, pueblos, casas y patios, mobiliario, configuración de las ciudades, medios de transporte, agricultura, ganaderia, actividad industrial y saber y cultura populares.
Editada con las fotografias y dibujos tomados por el propio autor durante su estancia en la serrania entre septiembre y octubre de 1932, la obra nos puede revelar aspectos definitivamente perdidos o continuidades de la realidad rural andaluza desde el punto de vista de un exponente de la intelectualidad alemana de los años treinta. Pero tambièn nos descubre otros aspectos no menos interesantes precisamente sobre esa misma intelectualidad académica de la Alemania nacional-socialista y cualquier otra intelectualidad que bajo la apariencia de la objetividad cientifica esconde los sesgos y distorsiones de una visión preconcebida y cargada de prejuicios.

De ahi el titulo de esta reseña: la situación del etnólogo alemán recorriendo la Sierra de Cádiz y recopilando datos como si fuera un entomólogo diseccionando insectos no puede dejar de recordar a la de aquèl extraterrestre en la novela Sin noticias de Gurb de Eduardo Mendoza, ese acertado divertimento sobre la visión del extranjero que juzga mal lo que no comprende. Giese se considera cientifico y no debe juzgar, pero el despistado alienigena de la novela, tan analitico como atónito ante las realidades de la

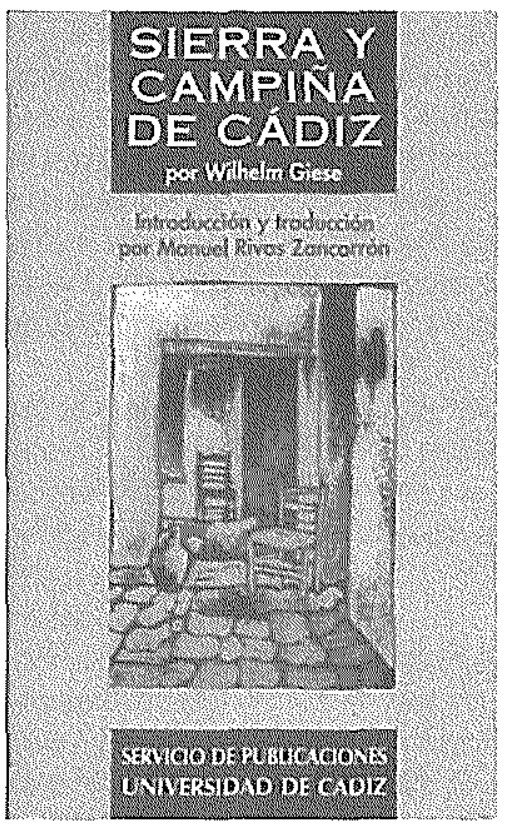
cultura catalana,.es tan objetivo y neutral como el sesudo alemán frente a la andaluza. Produce asombro observar cómo Giese mide al milimetro cada una de las partes que componen un determinado artilugio, cómo describe hasta el más minimo detalle los objetos, costumbres 0 expresiones más comunes para los lugareños sin llegar, en muchas ocasiones, a desentrañar su significado.

Veamos: en una ocasión, se ve privado del gusto de escuchar unos romances fronterizos porque Francisco Bocanegra, el narrador popular, se niega a ser entrevistado lápiz en ristre (p.346). Giese interpreta este gesto como un rechazo a la cultura escrita, pero lo que dijo Bocanegra fue que no queria un competidor que podia hacer dinero con sus historias sin ver èl un duro. La explicación de Giese sobre el origen del plato tipico "cojones de buey", muy arraigado desde las primeras culturas ganaderas, es más que peregrina: haciendo gala de su cosmopolitismo ilustrado, lo sitúa nada menos que en Argentina. La mezcla de lo profano y sagrado en Andalucia tambièn asombra pues "puede tener su origen en el recuerdo de que Almutadid (sic) de Sevilla debia entregar a Fernando I. los huesos de San Isidoro" (p.359) 
Pero donde más explicitamente lucen las ideas preconcebidas bajo el manto de la ciencia es en el apartado sobre los "Pueblos". Sabemos que fueron de un modo destacado los representantes de la muy alemana disciplina de la etnologia o Volkskunde que

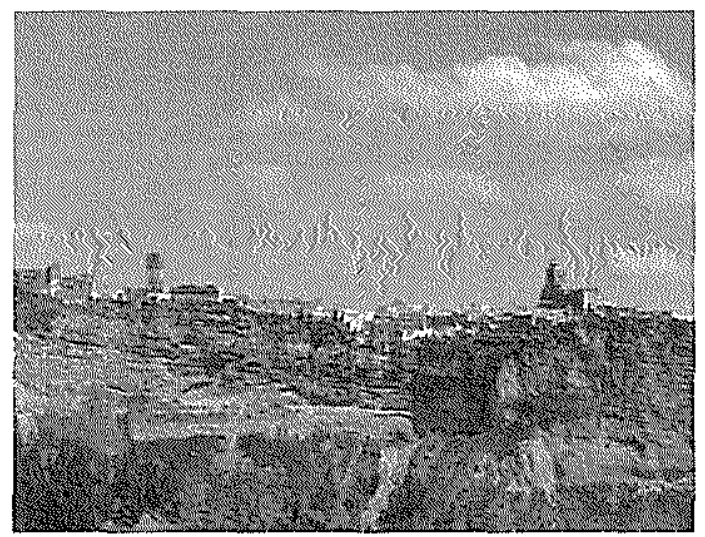
argumentaban en una mismalineacon la seudocientifica doctrina racista, fuerte corriente paneuropea que tiene sus raices en la contrarrevolución francesa. La confusión deliberada consiste sobre todo en el uso indiscriminado y acientifico de los conceptos de lengua, cultura y raza, siendo este último ya un concepto acientifico en si mismo. También en esta obra se trata de relacionar una forma fisica determinada con una raza concreta que es inventada ad hoc, por ejemplo la "raza mediterránea". La forma del cráneo o de la nariz lo dice todo: los braquicéfalos son africanos, y los morenos son de raza mediterránea (cf.p.73). Está claro que las chicas rubias son de origen racial nórdico, y las morenas beréberes. Por supuesto, los morenos se llevan la peor parte: "el braquicéfalo es signo de una clase social baja."(p.74). Con toda razón, Rivas califica estas aseveraciones de "salidas de tono" y no nos priva de la siguiente información en una nota a pie: "Téngase en cuenta que este estudio se acabó en Alemania en 1937, fecha en la que el nazismo estaba en pleno auge. $A$ esto ha de añadirse que la revista Volkstum und Kultur der Romanen, creada en Hamburgo en 1928 para acoger estudios folclóricos y etnográficos, y organo de publicación del Seminario Románico de esta universidad, al que pertenecia Giese, se erigió en 1938 en la portavoz de la lingüistica racista."(p.18)

No es de extrañar que esa lingüistica racista fuera sorda de un oído. Aunque si sorprende la falla de rigor y el cúmulo de desvarios de la obra precisamente en una disciplina como la fonética, altamente desarrollada ya desde el siglo XIX. Abundan los errores de transcripción fonética y la incoherencia de sus criterios. Contrasta, por ejemplo, la exactitud descriptiva de la [b] intervocálica con la confusión acerca de los sonidos velares y palatales, a los que continuamente aplica los rasgos castellanos conocidos por el autor, no los andaluces de la zona que realmente habria de oir, pero no oye: nadie en la Sierra dice [Xeréz], ni tampoco [púkaro] por 'búcaro'. (p.73), ni "[agara el padre a su niño de ra mano y lo dega a la ferja a komparle un xugete)" (p.347, el subrayado es mío) La forma dega merece un comentario, que casi se basta por si solo citando la nota del autor: "de DUCERE que sólo se ha mantenido hoy en compuestos (aduzir, conduzir). Igualmente llamativo que la conservación del verbo simple -en el sentido de 'ir', 'conducir' - es la forma del presente del subjuntivo. Se trata claramente de un subjuntivo -dega formado en castellano antiguo (-dugo) siguiendo el modelo del viejo yega (castellano antiguo yago [yacer]); cf. tb. con plega, que fue usado luego como indicativo al pasar el verbo a la clase $\mathrm{A}$. Cf. el uso de vienga y tienga en vez de tengo y vengo en Cuba" (p.372). Lo que en Cádiz se llama un [patináso], vamos. ¿De dónde se hatenido que sacar Giese esas formas del castellano antiguo sino de su poderosa mente que simplemente no conocia el uso transitivo del verbo llegar?

La traducción de Rivas es elegante y bien ligada. Sólo nos preguntamos por qué ha traducido "Sankt Jakob" por "San Jacobo" (p.359 ss.) y no "Santiago", nombre por el cual este santo es conocido en toda la hispanidad.

Tampoco queremos de jar de señalar los aciertos del texto original que no son pocos pero que se ven lastrados por los defectos arriba señalados. Giese señala, por ejemplo, un rasgo andaluz que sigue asombrando, divirtiendo o escandalizando al forastero y aun más a la forastera: "la naturalidad andaluza en los temas sexuales que es de una frescura ciertamente osada. Sin embargo, el andaluz la considera inofensiva ya que, de lo contrario, no la contaria en presencia de jovencitas". O sea, las pichas y chochos no son reprimidos en el texto, sino incluso adornados con sabios comentarios a pie de página.

El producto de estas investigaciones no tarda en ser designado como "exótico" en Alemania. Rivas Zancarón comenta: "Y es que los estereotipos, los clichés y demás elementos que dejan fosilizado el caracter y el modus vivendi de un pueblo se moldean siempre desde el exterior." La etiqueta de 'exótico' se coloca a lo ajeno, visto desde fuera con una visión enfrentada, simplemente porque no se corresponde con los cánones del espectador. Una postura atemporal que late tambièn en designaciones como 'folklórico' o 'étnico' - para todo lo que no sea académico, culto, europeo, occidental, comercial o germano. Imaginese si no lo 'exótico' que resulta el cambio de la guardia del Palacio de Buckingham a un indio tupi, o la complicada manera de andar de los humanos a los ojos del marciano que espera las noticias de Gurb.

En resumen: una obra interesante e ilustrativa en muchos sentidos.

Ch. E. 